\title{
A IMPORTÂNCIA DA PARTICIPAÇÃO DO PAI NO CICLO GRAVÍDICO PUERPERAL: uma revisão bibliográfica
}

\section{THE IMPORTANT PARTICIPATION THE FATHER IN THE DURING REGNANCY PUERPERIUM: a literature review}

\author{
Anamaria Donato de Castro Petito \\ Faculdade de Enfermagem, FACER Faculdades Unidade de Ceres-GO \\ anamariapetito@gmail.com
}

\author{
Aline Cristina Freitas Cândido \\ Faculdade de Enfermagem, FACER Faculdades Unidade de Ceres-GO \\ line_cristina14@hotmail.com

\section{Lorene Oliveira Ribeiro} \\ Faculdade de Enfermagem, FACER Faculdades Unidade de Ceres-GO \\ lorene_ribeiro@hotmail.com

\section{Guilherme Petito} \\ Mestre em genética, Faculdade de Farmácia, FACER Faculdades Unidade de Ceres-GO \\ guilherme.petito@gmail.com
}

\section{Endereço para correspondência:}

Av. Brasil, s/n, qd. 13

Morada verde ceres - Go,

Fone: (62) 3323-1040,

E-mail: anamariapetito@gmail.com

\section{RESUMO:}

Introdução: Para desenvolver com êxito a paternidade o homem precisa aperfeiçoar algumas habilidades como autoridade, saber impor-se, oferecer afeto. Hoje os serviços de saúde têm enfrentado um grande desafio, incluir o homem na rotina que antes era voltada somente para a mulher. É durante o pré-natal que o pai tem o primeiro contanto com o filho, aproximando-se mais da mulher, facilitando assim um parto e pós-parto considerados adequados. Objetivo: Levantar produções científicas sobre a importância da participação do pai no ciclo gravídico puerperal. Metodologia: A pesquisa foi realizada através de revisão bibliográfica, buscando artigos publicados na Biblioteca Virtual de Saúde (BVS), tendo como base de dados a Literatura Latino-Americana e do Caribe em Ciências da Saúde (LILACS), publicados entre 2007 e 2014, que respondiam a questão norteadora: Quais benefícios há na inserção do pai no ciclo-gravídico puerperal? Ao final, foram selecionados 13 artigos que compõem este estudo. Resultados e Discussão: A participação do pai durante o ciclo gravídico-puerperal é de total relevância, trazendo para mulher segurança e acalmando a mesma, fazendo com que assim ela se sinta mais feliz e tranquila nesse período, diminuindo o uso de intervenções e medicações durante o parto, possibilitando dessa forma que ele adquira um maior vínculo com a mãe e o bebê. Considerações finais: Ressalta-se a importância da participação do pai em todo ciclo gravídico-puerperal, evidenciando os benefícios que o mesmo traz quando se mostra efetivo, aumentando a segurança da mulher, reduzindo o tempo de trabalho de parto trazendo assim um vínculo familiar consistente. 
Descritores: Enfermagem; Pré-Natal; Parto Obstétrico; Paternidade e Puerpério.

\begin{abstract}
:
Introduction: To successfully develop fatherhood the man needs to improve some skills as authority, whether to impose upon, offer affection. Today health the services have faced a great challenge, to include the man in the routine that was previously focused only on women. It is during the prenatal that the father has the first contact with the son, approaching the woman, facilitating thus childbirth and postpartum considered adequate. Objective: The aim was to emphasize the importance of father involvement in pregnancy and childbirth. Methodology: The survey was conducted based on a review to find articles published in the Virtual Health Library (VHL), whose database the Latin American and Caribbean Health Sciences (LILACS), published between 2007 and 2014, who answered the guiding question: What benefits there are in his father's insertion in childbirth - pregnancy? At the end, we selected 13 articles that comprise this study. Results and Discussion: The participation of the father during pregnancy and childbirth is entirely relevant, bringing woman security and calming the same, thus making her feel happier and quiet during these periods, reducing the use of interventions and medications for delivery, thus enabling it to acquire a greater bond with the mother and the baby. Final Thoughts: We emphasize the importance of parent participation throughout pregnancy and childbirth, highlighting the benefits it brings when it is effective, increasing women's safety, reducing labor time bringing a consistent family ties .
\end{abstract}

Descriptors: Nursing; Prenatal; Obstetric delivery; Fatherhood and Puerperium 


\section{INTRODUÇÃO}

No Ocidente a paternidade estava relacionada à política e a religiosidade, ligada diretamente à imagem suprema, pois Deus era visto como o pai da humanidade, o rei, o pai da nação e o pai de família, o responsável e dono de sua mulher e de seus filhos. Dessa forma, o pai tinha como missão manter o nível de vida do seu filho e zelar pela sua educação (CÚNICO; ARPINI, 2013).

A paternidade está relacionada com a definição de masculinidade que é a "qualidade de masculino ou de másculo; virilidade" (CARVALHO, 2009), pois está ligada com a "figura do macho", colocando em evidência a sua virilidade. A construção da identidade paterna depende de vários fatores: como a influência do meio e como o homem foi inserido e educado na sociedade (AMARO, 2008).

Para desenvolver com êxito a paternidade o homem precisa aperfeiçoar algumas habilidades como: autoridade, saber impor-se, oferecer afeto, ser um exemplo de masculinidade e relacionamento conjugal, apresentar alternativas para a vida, mostrar formas de progredir e ser um intermediário da relação entre mãe e filho (SETTON; PAZINATO, 2002).

A experiência de se ver pai, provoca no homem uma variável nos sentimentos, indo da felicidade para o descontentamento, da proximidade para o distanciamento. Os pais criam expectativas, como por exemplo, como será sua relação com o bebê e como desenvolverá seu papel paterno. Enquanto muitos não se imaginam desempenhando tal papel, outros planejam a educação e entrosamento com a criança, já pensam em como aconselhar e orientar, possibilitando que o filho obtenha o que o mesmo não teve oportunidade (GABRIEL; DIAS, 2011).

Hoje os serviços de saúde têm enfrentado um grande desafio, que é incluir o homem/pai (paternidade)na rotina que anteriormente era voltada somente para a mulher/mãe (maternidade). No começo da vida, diferente do que se pensa, normalmente o pai está presente de alguma maneira, passando pelas unidades de saúde muitas vezes despercebido. A maior dificuldade é fazer com que este homem/pai se sinta reconhecido e tenha chance de obter informações, dividir experiências, adquirir práticas no cuidado e na formação de vínculos com os filhos (BRANCO et al., 2009).

É durante o pré-natal que o homem/pai percebe a responsabilidade e a relevância que sua participação tem na vida da mulher/mãe e do feto, é nesse período que ele terá o primeiro contato com o feto (batimentos cardiofetais, visualização do bebê através da ultrassonografia) 
e a percepção do desenvolvimento, fazendo com que o casal se aproxime mais, compartilhando esse momento onde ocorrem tantas mudanças (OLIVEIRA et al., 2009; BENAZZI; LIMA; SOUSA, 2011).

A participação e o apoio afetivo oferecido pelo pai do bebê, auxilia a mulher a tolerar com maior facilidade as dores e ansiedade do trabalho de parto, traz vantagens como: diminui o tempo do trabalho de parto, número de analgésicos e medicações que induzem a dilatação, o uso de fórceps, reduz a sensação de dor, os números de cesarianas e o tempo de internação dos recém-nascidos nos hospitais, assim como, melhora a impaciência da mulher. Dessa forma, ela demonstra maior contentamento com a experiência do nascimento (JARDIM; PENNA, 2012).

O período do pós-parto é caracterizado pela dúvida, aumento do compromisso, diminuição do tempo de descanso (sono), os homens se preocupam com a falta de atenção por parte da mulher quanto ao casamento. O homem se sente frustrado por não ter pela mulher o reconhecimento do seu desejo em participar nos cuidados com o bebê, pois o mesmo tem um período de tempo pequeno para consolidar a relação com o filho, causando desarmonia entre o casal (OLIVEIRA, 2007).

Tanto o pai como a mãe tem igual importância na participação do crescimento e amadurecimento do filho, não só âmbito material, mas também na afetiva. Quando o bebê nasce o pai se sente sem espaço para expressar o que está sentindo, pois a atenção está toda voltada para mãe e o bebê, se sentindo assim rejeitado e excluído, sem espaço junto à esposa/mãe, podendo assim surgir sentimentos como o egoísmo, afastando-se quando a amamentação se inicia (PIAZZALUNGA; LAMOUNIER, 2009).

Dessa forma, é de grande relevância, que os profissionais de saúde minimizem a distância que já se faz histórica, dos então pais com o serviço de saúde, desenvolvendo práticas que servem para revisar a importância da família, paternidade e maternidade, que sem dúvida trará grandes benefícios para a criança (BRANCO et al., 2009).

Portanto este trabalho teve como principal objetivo, levantar produções científicas sobre a importância da participação do pai no ciclo gravídico puerperal, sob o aspecto de vínculo afetivo e segurança. Assim como, evidenciar os benefícios da participação efetiva do pai no decorrer da gestação, parto e puerpério, conhecendo a influência da presença do pai/companheiro no desenvolvimento do sentimento de segurança na mulher durante o parto e enfatizar a importância da enfermagem na inclusão do pai desde a gestação até o puerpério. 


\section{METODOLOGIA}

A proposta de investigação que conduziu esta revisão foi: "A importância da participação do pai no ciclo gravídico puerperal". A pesquisa foi realizada através de revisão bibliográfica, buscando artigos publicados na Biblioteca Virtual de Saúde, tendo como base de dados a Literatura Latino-americana e do Caribe em Ciências da Saúde. Tendo a proposta de investigação estabelecida, buscou-se realizar a pesquisa bibliográfica usando os seguintes descritores de forma combinada: Enfermagem; Pré-Natal; Parto Obstétrico; Paternidade e Puerpério.

Foram incluídos no estudo, artigos completos, relacionados com o assunto proposto, publicados entre 2007 à 2014 e excluídos estudos fora do contexto nacional conforme figura 1.

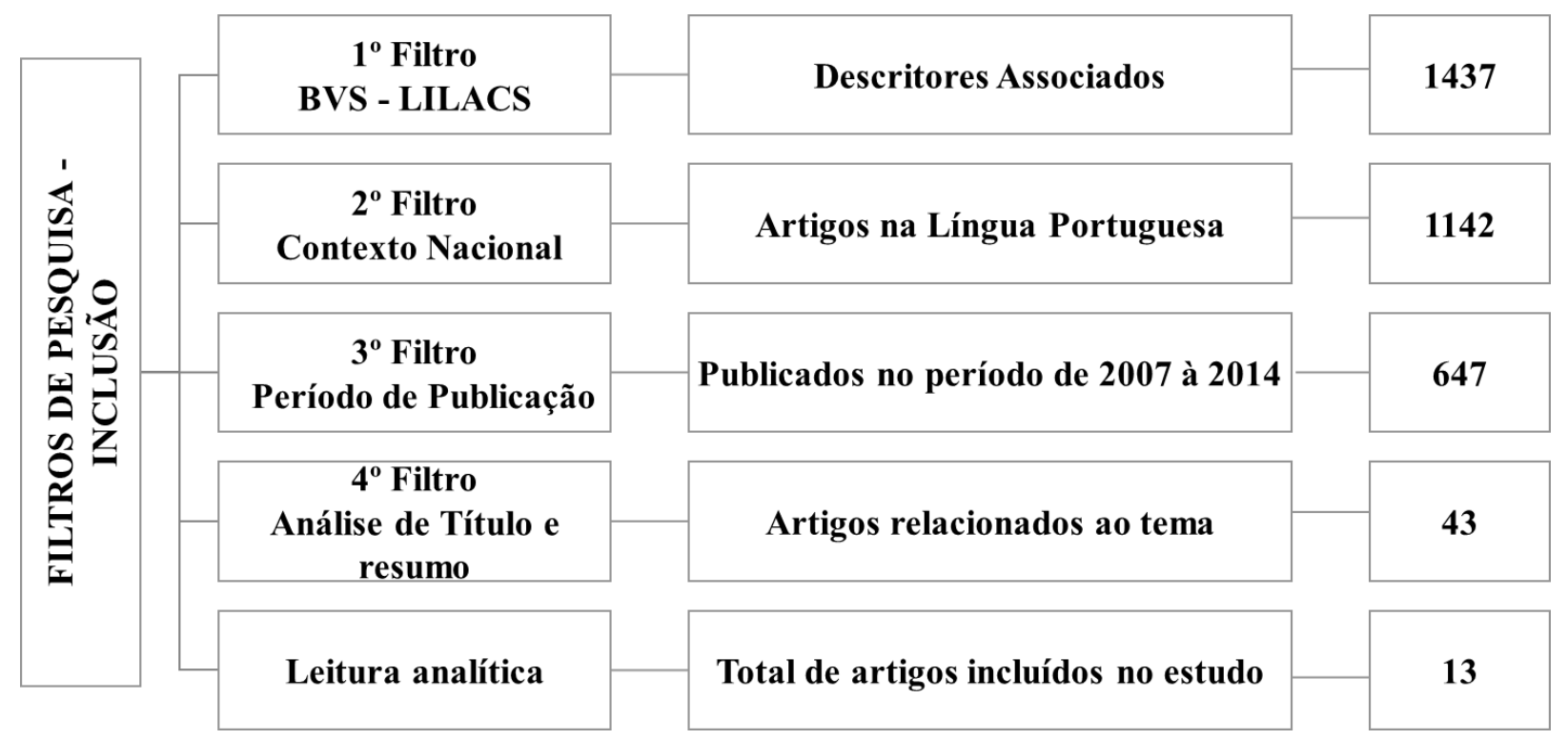

Figura 1: Trajetória metodológica dos artigos pesquisados

\section{RESULTADOS E DISCUSSÃO}

O envolvimento do homem com a saúde da mulher, se deu a partir da Conferência Internacional de População e Desenvolvimento do Cairo em 1994, impulsionando assim, a criação de políticas públicas, tendo como finalidade a promoção da participação dos homens nos diversos âmbitos à saúde da mulher. Por conseguinte houve um aumento do interesse masculino, no que diz respeito à saúde da mulher. Neste contexto o homem tem sido mais ativo quando suas mulheres estão gestantes, sendo muitas vezes participantes ativos nos pré-natais, também se teve um aumento da inserção do homem no trabalho de parto, parto e pós-parto, 
tendo o devido respaldo pela Lei $\mathrm{n}^{\circ} 11.108$, de 7 de Abril de 2005, que assegura o direito da mulher de ter um acompanhante de sua escolha, sendo este de preferência o pai do bebê (REBERTE; HOGA, 2010; PERDOMINI, 2010).

Tabela1: Benefícios da participação efetiva do pai do decorrer do ciclo gravídico puerperal

\begin{tabular}{|c|c|c|c|c|}
\hline AUTOR & TÍTULO DO ARTIGO & OBJETIVO & ANO & PERIÓDICO \\
\hline $\begin{array}{l}\text { TOMELERI et } \\
a l\end{array}$ & $\begin{array}{c}\text { Eu vi meu filho nascer: } \\
\text { vivência dos pais na sala de } \\
\text { parto }\end{array}$ & $\begin{array}{l}\text { Apreender o conhecimento dos pais } \\
\text { sobre o direito do acompanhante } \\
\text { durante o trabalho de parto e parto e } \\
\text { conhecer a vivência dele durante o } \\
\text { nascimento do filho }\end{array}$ & 2007 & $\begin{array}{l}\text { Rev. Gaúcha } \\
\text { Enferm. Porto } \\
\text { Alegre (RS) }\end{array}$ \\
\hline $\begin{array}{c}\text { BRITO; } \\
\text { OLIVEIRA; } \\
\text { CARVALHO }\end{array}$ & $\begin{array}{l}\text { Percepção do homem sobre } \\
\text { o pós parto da } \\
\text { mulher/companheira }\end{array}$ & $\begin{array}{c}\text { Verificar o entendimento do homem } \\
\text { acerca do pós parto da companheira e } \\
\text { identificar suas atitudes nessa fase da } \\
\text { vida do casal }\end{array}$ & 2008 & Rev. Eletr. Enf. \\
\hline $\begin{array}{l}\text { OLIVEIRA; } \\
\text { BRITO }\end{array}$ & $\begin{array}{c}\text { Ações de cuidado } \\
\text { desempenhadas pelo pai no } \\
\text { puerpério }\end{array}$ & $\begin{array}{c}\text { Analisar as ações desenvolvidas pelo } \\
\text { homem durante o puerpério de sua } \\
\text { companheira }\end{array}$ & 2009 & $\begin{array}{l}\text { Esc. Anna Nery } \\
\text { Rev. } \\
\text { Enfermagem }\end{array}$ \\
\hline $\begin{array}{l}\text { OLINA; } \\
\text { NASCIMENTO } \\
\text {; SANTO }\end{array}$ & $\begin{array}{l}\text { Percepções e experiências } \\
\text { de homens relativas ao pré- } \\
\text { natal e parto de suas } \\
\text { parceiras }\end{array}$ & $\begin{array}{l}\text { Analisar a participação de homens no } \\
\text { pré-natal e parto de suas parceiras }\end{array}$ & 2010 & $\begin{array}{l}\text { Rev. enferm. } \\
\text { UERJ, Rio de } \\
\text { Janeiro }\end{array}$ \\
\hline $\begin{array}{l}\text { REBERTE; } \\
\text { HOGA }\end{array}$ & $\begin{array}{c}\text { A experiência de pais } \\
\text { participantes de um grupo } \\
\text { de educação para saúde no } \\
\text { pré-natal }\end{array}$ & $\begin{array}{l}\text { Descrever a experiência de pais que } \\
\text { participaram em um grupo de } \\
\text { educação para a saúde realizada na } \\
\text { assistência pré-natal }\end{array}$ & 2010 & $\begin{array}{l}\text { Ciencia y } \\
\text { enfermeria XVI }\end{array}$ \\
\hline $\begin{array}{l}\text { BRUGGEMAN } \\
\text { N et al }\end{array}$ & $\begin{array}{l}\text { A inserção do } \\
\text { acompanhante de parto nos } \\
\text { serviços públicos de saúde } \\
\text { de santa Catarina, Brasil }\end{array}$ & $\begin{array}{l}\text { Descrever a inserção do } \\
\text { acompanhante de escolha da } \\
\text { parturiente durante o trabalho de parto } \\
\text { e pós parto imediato nos serviços } \\
\text { vinculados ao sistema único de saúde }\end{array}$ & 2013 & $\begin{array}{l}\text { Esc. Anna Nery } \\
\text { (impr.) }\end{array}$ \\
\hline VIEIRA et al & $\begin{array}{l}\text { Paternidade no Brasil: } \\
\text { revisão sistemática de } \\
\text { artigos empíricos }\end{array}$ & $\begin{array}{c}\text { Caracterizar a produção de artigos } \\
\text { empíricos envolvendo o tema } \\
\text { paternidade e sua contribuição para o } \\
\text { desenvolvimento infantil e para a } \\
\text { família }\end{array}$ & 2014 & $\begin{array}{l}\text { Arquivos } \\
\text { Brasileiros de } \\
\text { Psicologia; Rio } \\
\text { de Janeiro }\end{array}$ \\
\hline
\end{tabular}

Na tabela 1 identifica-se os estudos relacionados aos benefícios da participação efetiva do pai do decorrer do ciclo gravídico puerperal, onde a presença do homem na assistência ao pré-natal e à saúde da mulher ainda não é uma realidade frequente, pois o foco da assistência permanece voltado às necessidades das mulheres e de acordo com os mesmos, à atenção voltada a eles é insatisfatória, nota-se que quando são envolvidos em grupos de pré-natais há um 
aumento do comprometimento com a gestação após vivenciarem a ansiedade, preocupação, dúvidas e inseguranças de suas companheiras, havendo também por parte das gestantes um cuidado maior com sua saúde quando se tem a participação ativa dos seus parceiros (REBERTE; HOGA, 2010).

A inserção do pai nas consultas de pré-natal, determina sua inclusão em todo processo, essa participação constitui uma relevante atribuição dos futuros pais, contribuindo assim para melhoria de vida e do relacionamento do casal, que estarão mais afetivamente ligados um ao outro, facilitando assim o apoio oferecido pelo pai no pré-natal e também durante o parto (OLIVA; NASCIMENTO; SANTO, 2010).

A participação do pai durante o parto é o momento do primeiro contato direto com o filho, sem auxílio da mulher. A presença do pai no nascimento do bebê, contribui para o desenvolvimento da prática dos direitos no que diz respeito a reprodução de homens e mulheres no nosso país. Essa aproximação facilita o envolvimento do pai com o filho, fazendo com que o vínculo aconteça precocemente, é também uma forma de prevenção da violência infantil, abandono da família além de aumentar a participação do pai como cuidador (TOMELERI et al., 2007).

Os benefícios do amparo oferecido pelo pai da criança à mulher durante o trabalho de parto são inúmeros, sendo os principais: aumento dos partos vaginais/naturais, diminuição da ideia negativa que muitas vezes se tem sobre o nascimento, do tempo de trabalho de parto, número de cesarianas, uso de instrumentos para o parto vaginal e o número de recém-nascidos com baixo índice de Apgar no $5^{\circ}$ minuto de vida, ajudando assim nos cuidados com a mulher e o recém-nascido no período de pós-parto (BRUGGEMANN et al., 2013).

O puerpério é um período muito importante no ciclo gravídico puerperal, pois durante ele, tudo o que foi planejado em relação aos cuidados com o recém-nascido são colocados em prática, o pai, neste momento o intermediário das relações entre a mãe e o filho. O companheiro deve se mostrar acessível para cuidar tanto da criança, como das tarefas domésticas, evitando assim, o desgaste emocional da mulher, desenvolvendo o vínculo e a prática da paternidade. Estudos demonstram que quando o homem se mostra acessível a ajudar a esposa nos cuidados com o recém-nascido, ele está demonstrando que sabe o quanto a mulher e a criança precisam que ele dedique parte do seu tempo aos mesmos, diminuindo assim, os sentimentos negativos da mulher, facilitando o convívio familiar (OLIVEIRA; BRITO, 2009; VIEIRA et al., 2014). 
As mudanças que acontecem anatômica e fisiologicamente no corpo da mulher, como as mudanças psicológicas, podem tornar o período do puerpério muito difícil, a mulher pode se mostrar mais frágil e insegura, podendo esses sentimentos serem diminuídos com a participação e auxílio do homem, a relevância de sua ajuda, traz benefícios não só com o desenvolvimento das atividades diárias, vínculo com a mulher e família, mas também no desenvolvimento psicológicos da criança (BRITO; OLIVEIRA; CARVALHO, 2008).

Tabela 2: O pai como influência no desenvolvimento do sentimento de segurança da mulher durante o parto

\begin{tabular}{|c|c|c|c|c|}
\hline AUTOR & TÍTULO DO ARTIGO & OBJETIVO & ANO & PERIÓDICO \\
\hline TOMELERI et al & $\begin{array}{c}\text { Eu vi meu filho nascer: } \\
\text { vivência dos pais na sala } \\
\text { de parto }\end{array}$ & $\begin{array}{l}\text { Apreender o conhecimento } \\
\text { dos pais sobre o direito do } \\
\text { acompanhante durante o } \\
\text { trabalho de parto e parto e } \\
\text { conhecer a vivência dele } \\
\text { durante o nascimento do filho }\end{array}$ & 2007 & $\begin{array}{l}\text { Rev. Gaúcha } \\
\text { Enferm, Porto } \\
\text { Alegre(RS) }\end{array}$ \\
\hline PERDOMINI & $\begin{array}{l}\text { A participação do pai } \\
\text { como acompanhante da } \\
\text { mulher no processo } \\
\text { nascimento }\end{array}$ & $\begin{array}{l}\text { Conhecer a participação do pai } \\
\text { como acompanhante da } \\
\text { mulher durante o parto }\end{array}$ & 2010 & \\
\hline $\begin{array}{c}\text { GONZALEZ et } \\
a l\end{array}$ & $\begin{array}{l}\text { A percepção do } \\
\text { acompanhante no } \\
\text { processo do nascimento }\end{array}$ & $\begin{array}{l}\text { Conhecer a percepção do } \\
\text { acompanhante no processo do } \\
\text { nascimento. }\end{array}$ & 2012 & $\begin{array}{l}\text { Cogitare } \\
\text { Enfermagem }\end{array}$ \\
\hline $\begin{array}{l}\text { BRUGGEMANN } \\
\text { et al }\end{array}$ & $\begin{array}{c}\text { A inserção do } \\
\text { acompanhante de parto } \\
\text { nos serviços públicos de } \\
\text { saúde de santa Catarina, } \\
\text { Brasil }\end{array}$ & $\begin{array}{l}\text { Descrever a inserção do } \\
\text { acompanhante de escolha da } \\
\text { parturiente durante o trabalho } \\
\text { de parto e pós parto imediato } \\
\text { nos serviços vinculados ao } \\
\text { sistema único de saúde }\end{array}$ & 2013 & $\begin{array}{l}\text { Escola Anna Nery } \\
\text { Revista de } \\
\text { Enfermagem }\end{array}$ \\
\hline DODOU et al & $\begin{array}{c}\text { A contribuição do } \\
\text { acompanhante para a } \\
\text { humanização do parto e } \\
\text { nascimento: percepções } \\
\text { de puérperas }\end{array}$ & $\begin{array}{c}\text { Investigar a contribuição do } \\
\text { acompanhante durante o parto } \\
\text { e o nascimento, na perspectiva } \\
\text { de puérperas }\end{array}$ & 2014 & $\begin{array}{l}\text { Escola Anna Nery } \\
\text { Revista de } \\
\text { Enfermagem }\end{array}$ \\
\hline
\end{tabular}

Os autores descritos na tabela 2, demonstram a importância da presença do pai durante o parto, auxiliando a mulher a se sentir mais segura, pois o nascimento do filho é um episódio que marca a vida da mulher e de todos que estão a sua volta (criança, pai e família), que será lembrado por toda vida, formando vínculos e possibilitando transformações pessoais. A presença do pai durante o trabalho de parto faz com que as mulheres se sintam mais realizadas, 
contentes, amparadas emocionalmente, melhorando o bem-estar físico e psicológico da mulher (DODOU et al., 2014).

A presença do homem/pai, durante o parto é sem dúvidas de grande relevância, pois hoje os homens só estão impedidos de gestar e amamentar, sendo na maioria das vezes, participante efetivo em todos os momentos, principalmente durante o parto, fazendo com que a mulher se sinta mais segura e apoiada nesse momento, podendo massageá-la e ajudá-la na deambulação, demonstrando à ela tranquilidade, força e coragem, minimizando assim, o número de cesarianas, o uso de ocitocina e analgésicos, permitindo que as mulheres aumentem o contentamento com todo o processo de parturição (BRUGGEMANN et al., 2013; TOMELERI et al., 2007; PERDOMINI, 2010).

Esse episódio é marcante para mulher também pelas mudanças ocorridas fisiologicamente, estando interligado com sentimentos como: aflição, satisfação, tristeza e receio, é um período onde a mulher está muito frágil e vulnerável, tornando indispensável a participação do homem/pai como acompanhante. $\mathrm{O}$ homem/pai encoraja e deixa a mulher mais segura, reduzindo assim, o tempo do trabalho de parto, devido a adequada produção de hormônios fisiológicos durante o parto, gerando assim sentimentos de satisfação, confiança e felicidade, favorecendo para que a mesma tenha uma lembrança positiva do parto, contribuindo para melhora do vínculo familiar, e da assistência oferecida pela equipe de enfermagem (GONZALEZ et al; 2012).

Os autores descritos na tabela 3, ressaltam a humanização no ciclo gravídico puerperal, realizado pela equipe de enfermagem, onde se inicia durante o pré-natal, é nesse período que a gestante recebe educação em saúde, relacionada a ela, ao feto e como o pai será inserido A participação do pai em todo ciclo é de total relevância, onde os profissionais de enfermagem devem contribuir de forma que favoreça a convivência com o companheiro, possibilitando assim que o mesmo participe e compartilhe a experiência de ser pai, possibilitando que se forme vínculo pai-mãe-filho (FRIGO et al., 2013).

A assistência realizada pela equipe de enfermagem na inclusão do pai durante o parto, é um dos princípios básicos à humanização, o pai deve estar preparado para oferecer o apoio necessário durante a parturição, de acordo com o que foi lhe ensinado durante toda gestação pela enfermagem, dividindo com a mulher as aflições e receios que são comuns neste período, trazendo benefícios para a mulher como sentimentos positivos de segurança e alegria em compartilhar com o homem este momento (SANTOS et al., 2012). 
Tabela 3: A importância da enfermagem na inclusão do pai desde a gestação até ao parto

\begin{tabular}{|c|c|c|c|c|}
\hline AUTOR & TÍTULO DO ARTIGO & OBJETIVO & ANO & PERIÓDICO \\
\hline $\begin{array}{l}\text { OLIVEIRA; } \\
\text { BRITO }\end{array}$ & $\begin{array}{c}\text { Ações de cuidado } \\
\text { desempenhadas pelo pai no } \\
\text { puerpério }\end{array}$ & $\begin{array}{c}\text { Analisar as ações desenvolvidas } \\
\text { pelo homem durante o puerpério } \\
\text { de sua companheira }\end{array}$ & 2009 & $\begin{array}{l}\text { Esc. Anna Nery } \\
\text { Rev . } \\
\text { Enfermagem }\end{array}$ \\
\hline $\begin{array}{l}\text { SPINDOLA; } \\
\text { PROGIANT; } \\
\text { PENNA }\end{array}$ & $\begin{array}{l}\text { Opinião das gestantes sobre } \\
\text { acompanhamento da enfermeira } \\
\text { obstetra no pré-natal de um } \\
\text { Hospital Universitário }\end{array}$ & $\begin{array}{l}\text { Descrever a percepção das } \\
\text { gestantes em relação ao } \\
\text { atendimento da enfermeira obstetra } \\
\text { no acompanhamento do pré-natal }\end{array}$ & 2012 & $\begin{array}{l}\text { Ciencia y } \\
\text { Enfermaria } \\
\text { XVIII }\end{array}$ \\
\hline SANTOS et al & $\begin{array}{l}\text { Percepção da equipe de saúde } \\
\text { sobre a presença do } \\
\text { acompanhante no processo } \\
\text { parturitivo }\end{array}$ & $\begin{array}{c}\text { Analisar a percepção de } \\
\text { profissionais de saúde sobre a } \\
\text { presença do acompanhante durante } \\
\text { o processo parturitivo }\end{array}$ & 2012 & Rev Rene \\
\hline FRIGO et al & $\begin{array}{l}\text { Assistência de enfermagem e a } \\
\text { perspectiva da mulher no } \\
\text { trabalho de parto e parto }\end{array}$ & $\begin{array}{c}\text { Identificar as práticas da } \\
\text { assistência de enfermagem frente } \\
\text { ao trabalho de parto e parto em } \\
\text { hospital público e a perspectiva da } \\
\text { mulher neste processo }\end{array}$ & 2013 & $\begin{array}{l}\text { Cogitare } \\
\text { Enferm. }\end{array}$ \\
\hline
\end{tabular}

Contudo há por parte de alguns profissionais, o despreparo em lidar com o pai durante o parto, não direcionando a ele à atenção que o mesmo também necessita naquele momento, apoiando-o e incentivando-o nos cuidados com a mulher, dessa forma, se faz necessário que os profissionais em enfermagem tenham consciência da relevância que a participação do pai traz, e que sua participação também é muito importante no apoio ao casal, possibilitando que ambos tenham lembranças positivas do processo de parturição (SANTOS et al., 2012; FRIGO et al., 2013).

Considerando a atual realidade da equipe de enfermagem, tendo a inevitabilidade de atender e amparar não somente a mulher (gestante, parturiente ou puérpera), mas também seu marido/companheiro, certificando-se que ambos compartilhem sentimentos e experiências, possibilitando que construam suas identidades maternas e paternas (OLIVEIRA; BRITO, 2009).

Admitindo o puerpério como um episódio, que na maioria das vezes é desenvolvido, no contexto familiar, ou seja, mãe/pai/filho, a equipe de enfermagem atende a família em todos os ciclos de vida, nesse caso, tem-se por obrigação conhecer os aspectos que envolvem tal momento, para que assim possa de forma segura, inserir cada vez mais o pai no puerpério, 
permitindo assim, que o mesmo desenvolva com êxito seu papel, contribuindo para que a mulher se sinta amparada nos cuidados com o filho (OLIVEIRA; BRITO, 2009).

Nota-se então que a equipe de enfermagem é de suma importância para inclusão do pai no ciclo gravídico puerperal, começando essa inclusão no pré-natal, sendo este um período de envolvimento entre a equipe, a gestante e de quem esteja no seu contexto familiar, neste caso o pai, sendo o pré-natal a ocasião mais adequada para sanar dúvidas e trocar experiências, compreendendo mais facilmente o processo de gestação, melhorando a assistência à gestante através de ações educativas realizadas neste período, preparando-os para um parto e puerpério apropriados e seguros (SPINDOLA; PROGIANTI; PENNA, 2012).

\section{CONSIDERAÇÕES FINAIS}

O estudo possibilitou identificar e enfatizar a importância que a participação do pai tem em todo ciclo gravídico puerperal, onde o envolvimento do mesmo começa no pré-natal, permitindo maior aproximação entre o casal, contribuindo para um parto onde o companheiro conheça as necessidades da mulher, apoiando-a em todo período, fazendo com que assim o puerpério seja tranquilo e seguro, fechando esse ciclo de forma positiva para ambos.

Percebe-se a influência que o homem tem no desenvolvimento do sentimento de segurança da mulher durante o parto, possibilitando dessa forma observar que a mesma, se sente, mais segura, amparada, protegida, e que também tem o sentimento de satisfação, por poder dividir com o companheiro as dúvidas e ansiedades desse momento.

Demonstrou-se também a relevância que a equipe de enfermagem tem na inclusão do pai no ciclo gravídico e puerperal, sendo de suma importância que os profissionais da área tenham consciência dos benefícios que a participação do pai traz, fazendo com que essa pessoa tão importante, seja cada dia mais incluída nos cuidados com a saúde da mulher, principalmente quando a mesma estiver gestante, estendendo esses cuidados ao parto e puerpério, amparados sempre pelas orientações realizadas pela equipe de enfermagem, respeitando a individualidade de cada um dos participantes desse ciclo.

Espera-se que novos artigos sejam publicados sobre a importância de tal participação, ampliando a enfermagem como intermédio primordial entre a mulher, o homem e seu filho, pois a escassez de publicações sobre papel da enfermagem na inclusão do pai no ciclo gravídico 
e puerperal. Questiona-se: Qual seria o motivo de tamanha escassez de publicações que ressaltem a importância da enfermagem na inclusão do pai no ciclo gravídico puerperal?

\section{REFERÊNCIAS}

AMARO, E.C.V.M. Paternidade: novos e velhos valores. 2008 . Trabalho de Conclusão de Curso de Graduação apresentado à Escola de Serviço Social da Universidade Federal do Rio de Janeiro. Centro de filosofia e ciências humanas-Universidade Federal do Rio de Janeiro.

BENAZZI, A.S.T; LIMA, A.B.S; SOUSA.A.P. Pré-natal masculino: um novo olhar sobre a presença do homem. Rev. Pol. Pública .,São Luís, v. 15, n. 2, p. 327-333, jul-dez. 2011.

BRANCO, V.M.C. CARVALHO, M.L.M. COUTINHO, A.P.; SICURO, A. A Unidade de Saúde Parceria do Pai, $1^{\text {a }}$ edição: agosto de 2009. Disponível em < https://elosdasaude.files.wordpress.com/2011/01/unidade-de-sac3bade-parceira-do-pai.pdf > .

BRITO R.S; OLIVEIRA, E.M. F; CARVALHO, F.L.A. Percepção do homem sobre o pósparto da mulher/companheira. Rev. Eletr. Enferm., Rio Grande do Norte-Natal/RN, v.10, n. 4. p.1072-9, jul-set. 2008.

BRUGGEMANN, O.M, OLIVEIRA, M.E.; MARTINS, H.E.L.; GAYESKI, M.E.; ALVES, M.C. A inserção do acompanhante de parto nos serviços públicos de saúde de Santa Catarina, BRASIL. Rev. Esc. Anna Nery ., Santa Catarina, v. 17, n. 3 p. 432-438, jul-set. 2013.

- CARVAlho, L. B. Minidicionário Larousse da Língua Portuguesa. Editora Larousse n.1 p. 880 São Paulo,2009.

CÚNICO, S.D; ARPINI, D.M. A Família em mudanças: Desafios para a paternidade contemporânea. Rev. Pensando fam., Porto Alegre, v.17, n 1, p.28-40, jul. 2013.

DODOU,H.D.;RODRIGUES,D.P.;GUERREIRO,E.M.;GUEDES,M.V.C.;LAGO,P.N.;

MESQUITA,N.S.A contribuição do acompanhante para a humanização do parto e nascimento: percepções de puérperas. Rev. Esc. Anna Nery.,v. 18, n. 2 p. 262-269, abr-jun.2014.

FRIGO, J.; FERREIRA, D.G.; ASCARI, R.A.; MARIN, S.M.; ADAMY, E.K.; BUSNELLO, G. Assistência de enfermagem e a perspectiva da mulher no trabalho de parto e parto. Rev. Cogitare Enferm ., v. 18, n.4 p. 761-6, out-dez. 2013. 
GABRIEL, M.R; DIAS, A.C.G. Percepções sobre a paternidade: Descrevendo a si mesmo e o próprio pai como pai. Rev. Estudos de Psicologia ., v.16, n .3 p. 253-261, set-dez. 2011.

GONZALEZ, A.D, FERNANDES, E.S.; SILVA, E.F.; RABELO, M.; SOUZA, S.R.R.K.;

A Percepção do acompanhante no processo do nascimento.Rev. Cogitare Enferm ., v. 17, n. 2, p. 310-4, abr-jun.2012.

JARDIM, D.M.B; PENNA, C.M.M. Pai-Acompanhante e sua compreensão sobre o processo de nascimento do filho. REME-Rev. Min.Enf., v. 16, n. 3 p. 373-381, jul-set. 2012.

OLIVA, T.A; NASCIMENTO, E.R; SANTO, F.R.E. Percepções e experiências de homens relativas ao pré-natal e parto de suas parceiras. Rev. enferm. UERJ ., Rio de Janeiro, v .18, n. 3 p.435-40, jul-set. 2010.

OLIVEIRA, S.C.; FERREIRA, J.G.; SILVA, P.M.P.; FERREIRA, J.M.; SEABRA, R.A.; FERNANDO, V.C.N. A Participação do homem/pai no acompanhamento da assistência prénatal. Rev. Cogitare Enfermagem, v. 14, n.1 p.73-8, jan-mar. 2009.

OLIVEIRA, E.M.F. Vivência do homem no puerpério. 2011. 97f. Trabalho apresentado à banca examinadora do Programa de Pós-Graduação em Enfermagem da Universidade Federal do Rio Grande do Norte para obtenção do título de Mestre em Enfermagem. Rio Grande do Norte, Natal.

OLIVEIRA, E.M.F; BRITO, R.S. Ações de cuidado desempenhadas pelo pai no puerpério. Rev. Esc. Anna Nery Enferm ., v. 13, n.3 p. 595-601, jul-set. 2009.

PIAZZALUNGA, C.R.C; LAMOUNIER, J.A. A Paternidade e sua influência no aleitamento materno. Rev. Pediatria ., São Paulo, v .31, n. 1 p. 49-57, 2009.

PERDOMINI, F.R.I. A participação do pai como acompanhante da mulher durante o nascimento. 2010. 87 f. Dissertações apresentada ao Curso de Mestrado da Escola de Enfermagem da Universidade Federal do Rio Grande do Sul, como requisito parcial à obtenção do título de Mestre em Enfermagem e registro nesta Comissão. Rio Grande do Sul-Porto Alegre(RS).

REBETE, L.M; HOGA, L.A.K A. Experiência de pais participantes de um grupo de educação para saúde no pré-natal. Rev.Ciencia y Enfermeria XVI ., n. 1 p.105-114, 2010.

SANTOS, L.M.; CARNEIRO, C.S.; CARVALHO, E.S.S.; PAIVA, M.S. Percepção da equipe de saúde sobre a presença do acompanhamento no processo parturitivo. Rev Rene., Feira de Santana-BA, v. 13, n.5 p.994-1003, 2012. 
SETTON, M.Z; PAZINATO, P. Um estudo da paternidade: aproximação entre a abordagem relacional fenomenológica existencial e a abordagem relacional sistêmica. Boletim de Iniciação Cientifica em Psicologia ., São Paulo, v.3, n.1 p. 74-100, 2002.

SPINDOLA, T; PROGIANTI. J.M; PENNA, L.H.G. Opinião das gestantes sobre acompanhamento da enfermeira obstetra no pré-natal de um hospital universitário. Rev.Ciencia y Enfermeria XVIII ., Rio de Janeiro, n. 2, p. 65-73, 2012.

TOMELERI, K.R.;PIERI,F.M.;VIOLINI,M.R.;SERAFIM,D.;MARCON,S.S. Eu vi meu filho nascer: vivência dos pais na sala de parto. Rev. Gaúcha Enferm ., Porto Alegre, v. 28, n. 4 p. 497-504, dez. 2007.

VIEIRA, L.M, BOSSARDI, C.N. GOMES, L.B. BOLZEL, S.D.A. CREPALDI, M.A. PICCININI, C.A. Paternidade no Brasil: revisão sistemática de artigos empíricos. Arquivos Brasileiros de Psicologia .,Rio de Janeiro, v. 66, n. 2 p. 36-52, 2014. 